\title{
MPV and PDW as inflammatory indicators in chronic otitis media with effusion.
}

\author{
Ahmet Hamdi Kepekçi* \\ Yeni Yuzyil University, Istanbul, Zeytinburnu, Turkey
}

\begin{abstract}
Objectives: Chronic Otitis Media with Effusion (COME) is a clinical condition characterized by an effusion in the tympanic cavity. In this retrospective study, we aimed to compare the MPV and PDW value of patients with chronic otitis media with effusion (COMA) to those in healthy subjects as an inflammatory indicator.

Materials and methods: Demographic features: age, race and gender and laboratory parameters; White Blood Cell count (WBC), Red Blood Cell count (RBC), Hemoglobin (Hb), Hematocrit (Het), Platelets (PLT), MPV and PDW were recorded after obtaining from the computerized database.

Results: We included 149 patients who underwent ventilation tube insertion between with those of age and sex compatible 151 healthy subjects into the study. In our study no statistically significant differences were identified between paediatric patients diagnosed with COME and healthy controls in terms of WBC, RBC, Hb, Hct, and MPV levels $(p>0.05)$. However, we found significant differences both the platelet count $(p<0.05)$ and PDW levels $(p<0.001)$ between the COME and control group.

Conclusion: This study is the first to evaluate the relationship between PDW and COME. With regards to clinical and laboratory findings, novel inflammatory markers derived from routine hemogram test may be used.
\end{abstract}

Keywords: Mean platelet volume, Platelet activation, Otitis media with effusion, Inflammation.

Accepted on April 09, 2018

\section{Introduction}

Otitis media with effusion is a middle ear inflammatory disease. A variety of potent inflammatory mediators has been detected in middle ear effusions of children with OME [1].

Chronic Otitis Media with Effusion (COME) is a clinical condition characterized by an effusion in the tympanic cavity lasting longer than 3 months without an acute infection. Otitis media with effusion, a term synonymous with chronic nonsupportive otitis media, secretory otitis media, serous otitis media, and glue ear, is one of the most common chronic ontological conditions of childhood period. Thus, this condition can lead to the impairment of children's development of linguistic, behavioural, motor, and social skills [2-4].

If left untreated, it causes atelectatic tympanic membrane, adhesive middle ear disease, and cholesteatoma development, which may lead to a permanent hearing loss. Platelets have a critical role in homeostasis and tissue repair [5-7]. Moreover, recently it has been discovered that platelets also have a role in the inflammatory process. Platelet cytoplasmic granules contain several inflammatory products, including the Platelet Activation Factor (PAF), Platelet-Derived Growth Factor (PDGF), Platelet Factor-4 (PF4), beta-Thromboglobulin (bTg), Interleukin-1 (IL-1), leukotrienes, and prostaglandins $[8,9]$. Increased platelet activation plays an important role in the development of inflammation and it was found that platelets significantly contribute to chronic inflammation, and MPV may be used as a marker of inflammatory disease [10-12].

Mean Platelet Volume (MPV) and Platelet Distribution Width (PDW) are routine hematologic parameters used to measure and understand platelet activity. Young platelets with large volume have intense granules in their cytoplasm; enzymatically and metabolically they are much more active [13]. Since increased platelet activation has an important role in the inflammatory process, it can be used as an indicator of inflammation [10-12,14,15]. PDW shows differences in the size of platelets in circulation; an increase in the PDW level indicates that there are more different sizes of platelets in circulation, while a decrease in PDW indicates that there are more similar sized, old platelets in circulation [16].

In the present study, we have investigated the role of MPV and PDW as an inflammatory indicator in 149 paediatric patients with COME.

\section{Materials and Methods}

The MPV and PDW parameters were collected retrospectively from the files of 149 paediatric patients who underwent ventilation tube insertion operation for COME between 
December 2009 and December 2015. Patients with chronic inflammatory diseases, active infection, diabetes mellitus and malignancy were excluded. Subjects on treatment with an agent that may influence $\mathrm{CBC}$ parameters, such as aspirin or steroid, were also excluded. Control subjects were selected from healthy volunteers who visited outpatient clinics of our hospital for a routine check-up.

The blood samples were collected in sterile tubes containing a fixed amount of anticoagulant and analyzed in several minutes with ABX Micros automatic hematologic analyzer (ABX Micros: HORIBA, California, USA). Patient files were analyzed from the archives of the hospital computer automation program. Demographic features, namely age, race and gender; and laboratory parameters, i.e. White Blood Cell count (WBC), Red Blood Cell count (RBC), Hemoglobin (Hb), Hematocrit (Hct), Platelets (PLT), MPV, and PDW, were obtained and compared with those of the control group. Approval for the study was granted by the Hospital Ethics Committee. Data were analyzed using SPSS for Windows. Variables of qualitative data were expressed as numbers and percentages, while variables of quantitative data were expressed as means or min-max ranges. To compare the groups for the categorized variables, Mann-Whitney $U$ test was used for the quantitative variables. A p-value less than 0.05 are considered as statistically significant.

\section{Results}

Adenoidectomies and/or tonsillectomies were performed in 149 paediatric cases diagnosed with serous otitis media. We only performed adenoidectomy for which no inflammation was found in the histopathological examination in 149 cases which were included in the study. These parameters were analyzed statistically by comparing them with the MPV and PDW levels of the control group, which included randomly selected, 151 healthy children. The mean age of the study group was $6.75 \pm$ $2.67 \mathrm{y}$ (the minimum age was 2 and the maximum age was 16 y); the mean age of the control group was $6.69 \pm 3.66 \mathrm{y}$ (the minimum age was 2 and the maximum age was $16 \mathrm{y}$ ). The study group included $65(43.6 \%)$ female and $84(56.4 \%)$ male patients; the control group included $68(45.0 \%)$ female and 83 (55.0\%) male subjects. The mean MPV levels of the study and control groups were $7.53 \pm 0.98$ and $7.64 \pm 0.9$, respectively; there was no significant difference between the groups ( $p$ $=0.195)$. The mean PDW levels of the study and control groups were $13.35 \pm 1.85$ and $14.14 \pm 2.26$, respectively, and the difference between the two groups was significant $(p<0.05)$ (Figure 1). The mean platelet count of the study group was $330.65 \pm 90.91$; the mean platelet count of the control group was $307.64 \pm 76.18$. This difference was also significant $(\mathrm{p}=0.026)$ (Table 1).

Table 1. The parameters of sex, age, and hematologic findings in the COME and control groups.

\section{Study group $(n=149)$}

Control group $(n=151)$

\begin{tabular}{llll}
\hline Age $(\mathrm{y})$ & $6.75 \pm 2.67$ & $6.69 \pm 3.66$ & 0.601 \\
\hline $\mathrm{Sex}, \mathrm{F} / \mathrm{M}, \mathrm{n}(\%)$ & $65(43.6 \%) / 84(56.4 \%)$ & $68(45.0 \%) / 83(55.0 \%)$ & 0.806 \\
\hline $\mathrm{WBC}(/ \mu \mathrm{L})$ & $8.34 \pm 2.56$ & $8.03 \pm 2.9$ & 0.108 \\
\hline $\mathrm{RBC}(106 / \mu \mathrm{L})$ & $4.65 \pm 0.4$ & $4.66 \pm 0.38$ & 0.843 \\
\hline $\mathrm{Hb}(\mathrm{g} / \mathrm{dL})$ & $11.67 \pm 1.11$ & $11.89 \pm 1.04$ & 0.069 \\
\hline $\mathrm{Hct}(\%)$ & $36.23 \pm 3.13$ & $36.76 \pm 3.12$ & 0.162 \\
\hline $\mathrm{PLT}\left(\mathrm{K} / \mathrm{m}^{3}\right)$ & $330.65 \pm 90.91$ & $307.64 \pm 76.18$ & 0.026 \\
\hline $\mathrm{MPV}(\mathrm{fL})$ & $7.53 \pm 0.98$ & $7.64 \pm 0.9$ & 0.195 \\
\hline $\mathrm{PDW}$ & $13.35 \pm 1.85$ & $14.14 \pm 2.26$ & 0.001 \\
\hline
\end{tabular}

F: Female; M: Male; WBC: White Blood Cell count; RBC: Red Blood Cell count; $\mathrm{Hb}$ : Hemoglobin; Hct: Hematocrit; PLT: Platelets; MPV: Mean Platelet Volume; PDW: Platelet Distribution Width; \pm : Standard deviation. aStatistical analysis was performed with the Mann-Whitney U-test.

The study and control groups were tested according to the significance of the parameters. PDW $(p=0.001)$ showed variability, while MPV ( $p=0.195)$ did not show any variability in the comparison of the study and control group (Figure 1).

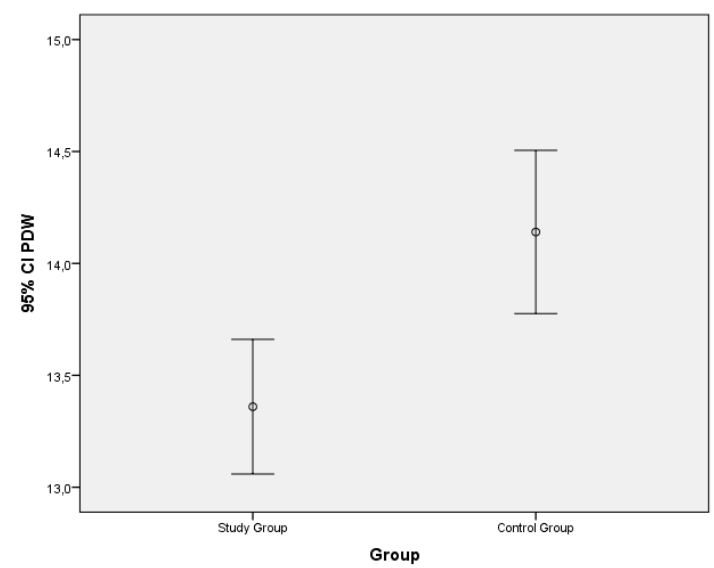

Figure 1. PDW averages in the COME and control group.

\section{Discussion}

In this study, we have evaluated COME and its association with MPV and PDW in paediatric patients. The main finding of this study was inflammatory markers derived from routine $\mathrm{CBC}$ tests useful for differentiation of patients with COME from healthy subjects. COME is an inflammatory disease of the middle ear. Eustachian tube dysfunction, adenoid hypertrophy, viral and bacterial infections, and allergies are important etiologic factors.

The inflammatory cells that infiltrate the middle ear mucosa secrete pro-inflammatory products like PAF, prostaglandins, leukotrienes, histamine, TNF- $\alpha$, interleukin- $1 \beta$, and interleukin 8 [17-20]. These inflammatory cytokines have been determined in both animal and human clinical studies [18,21,22]. Recently, it has been reported that platelets have a role in diseases characterized by systemic inflammation, and increased MPV may be used as a marker of inflammation [23-25]. In studies made with patients who have an inflammatory disease, such as 
rheumatoid arthritis, psoriasis, ankylosing spondylitis, and nasal polyposis, increased MPV values have been observed [24,26,27]. Sagit et al. reported that the MPV levels of nasal polyposis patients were significantly higher than those in the healthy control group [27,28]. Apuhan et al. described that decreased MPV in nasal polyposis was a statistically significant difference between study and control groups [29]. Thus, there are discrepancies in recent studies regarding levels of MPV in terms of inflammation and infection. Somuk et al. reported no statistically significant differences were identified between paediatric patients diagnosed with COME and healthy controls in terms of MPV levels [30]. Platelet distribution width is an indicator of platelet size heterogeneity. A high PDW value suggests a large range of platelet sizes due to swelling, destruction, immaturity, and high reactivity. In the recent studies of Ozturk et al. PDW has been found to be associated with several clinical situations [31]. In the literature review, high PDW levels were found in coronary artery disease, benign paroxysmal positional vertigo, pulmonary embolism, acute gangrenous appendicitis, obstructive sleep apnoea syndrome, preeclampsia, and preterm labor, in patients with nasal polyposis [32,33]. Ozturk et al. studied 175 patients with inflammatory bowel disease and found that there was a statistically significant decrease in PDW levels during disease exacerbation compared to healthy control subjects [31]. Ulu et al., in their study of 40 idiopathic sudden sensorineural hearing loss cases, reported that both the MPV and PDW levels were significantly higher in the study group compared to the control group [34]. In a study of 160 acute gangrenous appendicitis patients, it was reported that PDW was a much more accurate diagnostic test than MPV [35].

In our study, the platelet count was higher in the study group $(p<0.05)$. The PDW level was lower in our study group than in the control group $(p<0.001)$. We think that middle ear disease with effusion is a localized inflammation and it has no impulse effect on bone marrow to produce young and active platelets.

Although our study has a limitation due to retrospective character, it has shown that the increase in PDW levels was an inflammatory sing in COME. In the case of high PDV level in adenoidectomy operation, care should be taken for inflammation. So, MPV and PDW data might be useful as an additional inflammatory marker of COME. Thus, prospective and controlled studies are needed to confirm PDW level as an additional marker in COME patients.

\section{Conflict of Interest}

No conflict of interest was declared by the authors.

\section{Financial Disclosure}

The authors declare that this study received no financial support.

\section{Ethics Committee}

This information was obtained retrospectively from the archives of the hospital's computer automation program. The study was conducted with data from human beings.

\section{References}

1. Bernstein JM. Biological mediators of inflammation in middle ear effusions. Ann Otol Rhinol Laryngol 1976; 85: 90-96.

2. de Miguel MI, Macías ÁR. Serous otitis media in children: implication of Alloiococcus otitidis. Otol Neurotol 2008; 29: 526-530.

3. Serbetcioglu B, Ugurtay O, Kirkim G, Mutlu B. No association between hearing loss due to bilateral otitis media with effusion and Denver-II test results in preschool children. Int J Pediatr Otorhinolaryngol 2008; 72: 215-222.

4. Eser O, Ipci K, Alp S, Akyol U, Unal O, Hascelik G. Efficacy of nasopharyngeal culture in identification of pathogens in middle ear fluid in chronic otitis media with effusion. Indian J Med Microbiol 2009; 27: 237.

5. Polińska B, Matowicka-Karna J, Kemona H. Assessment of the influence of the inflammatory process on the activation of blood platelets and morphological parameters in patients with ulcerative colitis (colitis ulcerosa). Prostaglandins 2011; 12: 16.

6. Bachert C, Wagenmann M, Hauser U, Rudack C. IL-5 synthesis is upregulated in human nasal polyp tissue. J Allergy Clin Immunol 1997; 99: 837-842.

7. Simon HU, Yousefi S, Schranz C, Schapowal A, Bachert C, Blaser K. Direct demonstration of delayed eosinophil apoptosis as a mechanism causing tissue eosinophilia. J Immunol 1997; 158: 3902-3908.

8. Grove EL, Hvas A-M, Kristensen SD. Immature platelets in patients with acute coronary syndromes. Thromb Haemost 2009; 101: 151-156.

9. Jagroop I, Mikhailidis D. Mean platelet volume is an independent risk factor for myocardial infarction but not for coronary artery disease. Brit J Haematol 2003; 120: 169-170.

10. Endler G, Klimesch A, Sunder-Plassmann H, Schillinger M, Exner M, Mannhalter C. Mean platelet volume is an independent risk factor for myocardial infarction but not for coronary artery disease. Brit J Haematol 2002; 117 : 399-404.

11. Kisacik B, Tufan A, Kalyoncu U, Karadag O, Akdogan A, Ozturk MA. Mean platelet volume (MPV) as an inflammatory marker in ankylosing spondylitis and rheumatoid arthritis. Joint Bone Spine 2008; 75: 291-294.

12. Tuncel T, Uysal P, Hocaoglu AB, Erge DO, Karaman O, Uzuner $\mathrm{N}$. Change of mean platelet volume values in asthmatic children as an inflammatory marker. Allergologia Et Immunopathologia 2012; 40: 104-107.

13. Kamath S, Blann A, Lip G. Platelet activation: assessment and quantification. Eur Heart J 2001; 22: 1561-1571. 
14. Yüksel O, Helvacı K, BaŞar Ö, Köklü S, Caner S, Helvacı $\mathrm{N}$. An overlooked indicator of disease activity in ulcerative colitis: mean platelet volume. Platelets 2009.

15. Mimidis K, Papadopoulos V, Kotsianidis J, Filippou D, Spanoudakis E, Bourikas G. Alterations of platelet function, number and indexes during acute pancreatitis. Pancreatology 2004; 4: 22-27.

16. Ka P. Platelet distribution width: a simple, practical and specific marker of activation of coagulation. Hippokratia 2010; 1: 2-32.

17. Jung TT. Prostaglandins, leukotrienes, and other arachidonic acid metabolites in the pathogenesis of otitis media. Laryngoscope 1988; 98: 980-993.

18. Rhee C-K, Jung TT, Miller S, Weeks D. Experimental otitis media with effusion induced by platelet activating factor. Ann Otol Rhinol Laryngol 1993; 102: 600-605.

19. Sato K, Liebeler CL, Quartey MK, Le CT, Giebink GS. Middle ear fluid cytokine and inflammatory cell kinetics in the chinchilla otitis media model. Infection Immunity 1999; 67: 1943-1946.

20. Smirnova MG, Kiselev SL, Gnuchev NV, Birchall JP, Pearson JP. Role of the pro-inflammatory cytokines tumor necrosis factor-alpha, interleukin-1 beta, interleukin-6 and interleukin- 8 in the pathogenesis of the otitis media with effusion. Eur Cytokine Network 2001; 13: 161-172.

21. Yellon RF, Leonard G, Marucha PT, Craven R, Carpenter RJ, Lehmann WB. Characterization of cytokines present in middle ear effusions. Laryngoscope 1991; 101: 165-169.

22. Jung T, Park Y, Schlund D, Weeks D, Miller S, Wong O. Effect of prostaglandin, leukotriene, and arachidonic acid on experimental otitis media with effusion in chinchillas. Annals Otol Rhinol Laryngol Supplement 1990; 148: 28-32.

23. Vizioli L, Muscari S, Muscari A. The relationship of mean platelet volume with the risk and prognosis of cardiovascular diseases. Int J Clin Pract 2009; 63: 1509-1515

24. Yazici S, Yazici M, Erer B, Erer B, Çalik Y, Bulur S. The platelet functions in patients with ankylosing spondylitis: anti-TNF- $\alpha$ therapy decreases the mean platelet volume and platelet mass. Platelets 2010; 21: 126-131.

25. Gasparyan AY, Stavropoulos-Kalinoglou A, Toms TE, Douglas KM, Kitas GD. Association of mean platelet volume with hypertension in rheumatoid arthritis. Inflamm Allergy-Drug 2010; 9: 45-50.
26. Karabudak O, Eralp Ulusoy R, Akyol Erikci A, Solmazgul E, Dogan B, Harmanyeri Y. Inflammation and hypercoagulable state in adult psoriatic men. Acta dermato-venereologica 2008; 88: 337-340.

27. Sagit M, Cetinkaya S, Dogan M, Bayram A, Vurdem U, Somdas M. Mean platelet volume in patients with nasal polyposis. B-ENT 2011; 8: 269-272.

28. Aktas G, Sit M, Tekce H, Alfelik A, Savli H, Simsek T. Mean platelet volume in nasal polyps. West Indian Med J 2013; 62: 515-518.

29. Apuhan T, Aktas G. Association between nasal polyps and novel inflammatory parameters. Biomed Res 2017; 28.

30. Somuk BT, Soyalıç H, Koc S, Gürbüzler L, Doğru S, Eyibilen A. Mean platelet volume as an inflammatory marker of chronic otitis media with effusion. Int J Pediatr Otorhinolaryngol 2014; 78: 1958-1960.

31. Öztürk Z, Dag M, Kuyumcu M, Cam H, Yesil Y, Yilmaz N. Could platelet indices be new biomarkers for inflammatory bowel diseases. Eur Rev Med Pharmacol Sci 2013; 17: 334-341.

32. Celikbilek A, Tanik N, Zararsiz G, Celikbilek M. Do platelet indices have a role in benign paroxysmal positional vertigo? Neurol Res 2014; 36: 763-768.

33. Kepekçi AH, Dizdar G, Kepekçi AB. Platelet distribution width (PDW) data of patients with nasal polyposis: is it important for clinical severity? ENT Updates 2017; 7: 33.

34. Ulu S, Ulu MS, Ahsen A, Yucedag F, Aycicek A, Celik S. Increased levels of mean platelet volume: a possible relationship with idiopathic sudden hearing loss. Eur Archiv Oto-Rhino-Laryngol 2013; 270: 2875-2878.

35. Fan Z, Pan J, Zhang Y, Wang Z, Zhu M, Yang B. Mean platelet volume and platelet distribution width as markers in the diagnosis of acute gangrenous appendicitis. Dis Markers 2015; 2015.

\section{*Correspondence to}

Ahmet Hamdi Kepekçi

Yeni Yuzyil University

Istanbul

Zeytinburnu

Turkey 